\title{
CTLA-4 polymorphisms associate with breast cancer susceptibility in Asians: a meta-analysis
}

Zhiming Dai ${ }^{1,2}$, Tian Tian ${ }^{1}$, Meng Wang ${ }^{1}$, Xinghan Liu ${ }^{1}$, Shuai Lin ${ }^{1}$, Pengtao Yang ${ }^{1}$, Kang Liu ${ }^{1}$, Yi

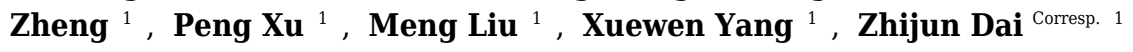

1 Department of Oncology, Second Affiliated Hospital of Xi'an Jiaotong University, Xi'an, China

2 Department of Anesthesia, Second Affiliated Hospital of Xi'an Jiaotong University, Xi'an, China

Corresponding Author: Zhijun Dai

Email address: dzj0911@xjtu.edu.cn

Previous studies have investigated the association between cytotoxic T-lymphocyte antigen-4 (CTLA-4) polymorphisms and breast cancer susceptibility, but the results remained inconsistent. Therefore, we evaluated the relationship between four common CTLA-4 polymorphisms and breast cancer risk by a meta-analysis, aiming to derive a comprehensive and precise conclusion. We searched EMBASE, Pubmed, Web of Science, $\mathrm{CNKI}$, and Wanfang databases until July 18th, 2016. Finally, ten eligible studies involving 4544 breast cancer patients and 4515 cancer-free controls were included and all these studies were from Asian. Odds ratio $(\mathrm{OR})$ and $95 \%$ confidence interval $(\mathrm{Cl})$ were used to evaluate the breast cancer risk in five genetic models. The results indicated that CTLA-4 $+49 A>G$ (rs231775) polymorphism had a significant association with decreased breast cancer risk in allelic, homozygous, dominant and recessive models. And +6230G >A (rs3087243) polymorphism reduced breast cancer risk specially in Chinese population under homozygous and recessive models. In contrast, -1661A>G (rs4553808) polymorphism increased breast cancer risk in allelic, heterozygous and dominant models. Whereas -1722 T>C (rs733618) did not relate to breast cancer risk. In conclusion, CTLA-4 polymorphisms significantly associate with breast cancer susceptibility in Asian population and different gene loci may have different effects on breast cancer development. Further large-scale studies including multi-racial population are required to confirm our findings. 
1 CTLA-4 polymorphisms associate with breast cancer susceptibility in Asians:

2

3

4

5

6 1. Department of Oncology, Second Affiliated Hospital of Xi'an Jiaotong University, Xi'an 7 710004, China;

8 2. Department of Anesthesia, Second Affiliated Hospital of Xi'an Jiaotong University, Xi'an 9710004 , China.

10

11 \# co-first authors

12

13

14

15

16

17

18

19

20

21

22

23

24

\section{a meta-analysis}

Zhiming Dai 1, 2, \#, Tian Tian", \#, Meng Wang1, \#, Xinghan Liu ${ }^{1}$, Shuai Lin ${ }^{1}$, Pengtao Yang1,

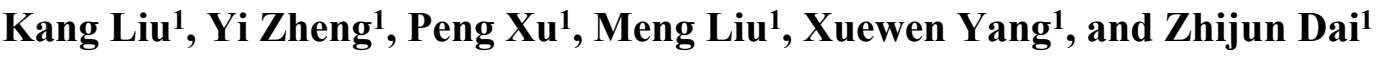
5

2

Correspondence author:

Zhi-Jun Dai

5

Email address: dzj0911@126.com 
26 Abstract

27 Previous studies have investigated the association between cytotoxic T-lymphocyte antigen-4

$28(C T L A-4)$ polymorphisms and breast cancer susceptibility, but the results remained inconsistent.

29 Therefore, we evaluated the relationship between four common CTLA-4 polymorphisms and breast cancer risk by a meta-analysis, aiming to derive a comprehensive and precise conclusion.

We searched EMBASE, Pubmed, Web of Science, CNKI, and Wanfang databases until July 18th, 2016. Finally, ten eligible studies involving 4544 breast cancer patients and 4515 cancer-free controls were included and all these studies were from Asian. Odds ratio (OR) and 95\% confidence interval (CI) were used to evaluate the breast cancer risk in five genetic models. The results indicated that $C T L A-4+49 \mathrm{~A}>\mathrm{G}(\mathrm{rs} 231775)$ polymorphism had a significant association with decreased breast cancer risk in allelic, homozygous, dominant and recessive models. And $+6230 \mathrm{G}>\mathrm{A}$ (rs3087243) polymorphism reduced breast cancer risk specially in Chinese population under homozygous and recessive models. In contrast, -1661A $>\mathrm{G}$ (rs4553808) polymorphism increased breast cancer risk in allelic, heterozygous and dominant models. Whereas $-1722 \mathrm{~T}>\mathrm{C}($ rs733618) did not relate to breast cancer risk. In conclusion, CTLA-4 polymorphisms significantly associate with breast cancer susceptibility in Asian population and

42 different gene loci may have different effects on breast cancer development. Further large-scale studies including multi-racial population are required to confirm our findings.

\section{Introduction}

Breast cancer has been the most common type of cancer and the main cause of cancer death among women in the world, which was estimated to have 1.7 million new cases in 2012(Torre et 
47 al. 2015). Breast cancer is an extremely heterogeneous disease in the clinic and the potential

48 molecular mechanism of carcinogenesis has not been clearly understood so far. In recent years,

49 inherited factors were identified to play a critical role in the development of breast cancer

50 (Reeves et al. 2012).

51 Researches on the field of tumour immunology found that the immune system can influence tumour occurence during the period of elimination, equilibrium and escape (Dunn et al. 2004).

Cytotoxic T-lymphocyte antigen-4 (CTLA-4), which was also designated as CD152, expressed mainly on activated $\mathrm{T}$ cells. As an immunosuppressive cytokine, it can inhibit T-lymphocyte proliferation and activation (Sun et al. 2008). Numerous researches have demonstrated that blockage of CTLA-4 function can improve antitumor immunity (Leach et al. 1996; Ribas et al. 2004; Vandenborre et al. 1999). This indicates CTLA-4 may exert positive effects on carcinogenesis. The human CTLA-4 gene, which locates in human chromosome $2 \mathrm{q} 33$, is one of the most important genes involved in immune responses to a variety of antigens (Walunas et al. 2011). CTLA-4 gene comprises four exons and has several important polymorphisms in the entire region, including the $+49 \mathrm{G}>\mathrm{A}(\mathrm{rs} 231775)$ in exon 1 (Donner et al. 1997), the $+6230 \mathrm{G}>\mathrm{A}$ (rs3087243) in 3'-untranslated region (Hughes 2006), the $-1661 \mathrm{~A}>\mathrm{G}$ (rs4553808) and -1722 $\mathrm{T}>\mathrm{C}$ (rs733618) in the promoter region (Johnson et al. 2001), which are the most commonly studied single nucleotide polymorphisms (SNPs). These SNPs are important because they can alter the host immune response by affecting the transcription of CTLA-4 gene, the expression of CTLA-4 protein, and the interaction of CTLA-4 and CD80 ligand (Anjos et al. 2002; Sun et al. 2008; Wang et al. 2002). 
Numerous investigations have demonstrated that $C T L A-4$ genetic polymorphisms may have

69

association with human breast cancer susceptibility (Erfani et al. 2006; Ghaderi et al. 2004; Li et al. 2012; Li et al. 2008; Minhas et al. 2014; Sun et al. 2008; Wang et al. 2007; Zhifu et al. 2015; Kong 2010). The results showed that some of the polymorphisms such as rs 733618 and rs4553808 may increase the breast cancer risk while other polymorphisms such as rs 231775 and rs3087243 may reduce the risk of breast cancer. Considering a single study does not have enough power to detect the overall effects, we conducted a meta-analysis which is a statistical analysis of the data from some collection of studies in order to synthesize the results to obtain a more reliable evaluation of the relationship between the four common SNPs in CTLA-4 gene and breast cancer susceptibility.

\section{Materials and methods}

Our meta-analysis was conducted according to the Preferred Reporting Items for Systematic Reviews and Meta-Analyses (PRISMA) guidelines(Moher et al. 2010).

\section{Search strategy}

We searched the databases of EMBASE, PubMed, Web of Science, Wanfang, as well as Chinese National Knowledge Infrastructure (CNKI) to identify all the relevant articles up to July 18th, 2016. Keywords for search were: "CTLA-4 or Cytotoxic T-lymphocyte antigen 4 or CD152", "polymorphism or variation or SNP or rs231775 or rs308724 or rs4553808 or rs733618", and "breast cancer". The eligible article must be published in English or Chinese. References in retrieved articles were also searched manually.

\section{Criteria for selection}


All studies selected for further meta-analysis must conform to the included criteria: 1) case-

90

control study conducted in human and investigated the association of SNPs in CTLA-4 with breast cancer susceptibility; 2) All the breast cancer patients were diagnosed by pathology or histology; 3) detailed data of the allele and genotype distributions are available; 4) the controls were cancer-free individuals. In addition, articles meet the following criteria were excluded: 1) articles that were reviews, conference abstracts, or repeat publications; 2) study design were based on family; 3) studies with no control groups. The quality of each included study was assessed by Newcastle-Ottawa Scale for case-control studies (Wells, et al. 2014).

\section{Data extraction}

According to the selection criteria, two authors (Zhiming Dai and Tian Tian) reviewed the literature independently and extracted the raw data and information from each eligible study including: first author, publication year, country of origin, racial ancestry, source of control, genotype method, total number of case and control, allele frequency and genotype distribution in case and control, and $P$ value of HWE in control. Any discrepancy was discussed between authors and refereed by Zhijun Dai to reach a consensus.

\section{Statistical analysis}

For each study, ORs and $95 \%$ CIs were computed to estimate the breast cancer risk associated with CTLA-4 polymorphisms. Pooled ORs were calculated under the following genetic models: allele comparison of B vs. A, homozygote of BB vs. AA, heterozygote of AB vs. $\mathrm{AA}$, dominant model of $(\mathrm{BB}+\mathrm{AB})$ vs. $\mathrm{AA}$ and recessive model of $\mathrm{BB} v s$. $(\mathrm{AA}+\mathrm{AB})$. Heterogeneity among studies were estimated by $\mathrm{I}^{2}$ test and chi $^{2}$-based Q statistic and significance 
110 was considered at $\mathrm{I}^{2}>50 \%$ (Higgins \& Thompson 2002). We adopted the random-effects model

111 to analyze the combined ORs if $\mathrm{I}^{2}$ value was greater than $50 \%$. Otherwise, a fixed-effects model

112 should be exerted (Petitti 2001). We carried out subgroup analysis to estimate the specific effects

113 of ethnicity and source of control. We also conducted a sensitivity analysis to assess the

114 consistency and stability of our meta-analysis by omitting individual study in turn. Additionally,

115 Begg's funnel plot and Egger's test were used to assess publication bias, and significance was

116 identified as $P<0.05$ (Begg \& Mazumdar 1994; Egger et al. 1997). All the statistical analyses

117 were implemented with the Review Manager (Version 5.3; Cochrane Collaboration, London, UK)

118 and STATA software (Version 12.0; Stata Corp, College Station, TX).

\section{Results}

120 Characteristics of included studies

121 Finally, 9 articles comprising 10 studies investigating $C T L A-4+49 \mathrm{~A}>\mathrm{G}$ (rs231775) and/or $122+6230 \mathrm{G}>\mathrm{A} \quad(\mathrm{rs} 3087243) \quad$ and $/$ or $\quad-1722 \quad \mathrm{~T}>\mathrm{C} \quad(\mathrm{rs} 733618)$ and/or $\quad-1661 \mathrm{~A} / \mathrm{G} \quad(\mathrm{rs} 4553808)$ 123 polymorphisms were identified for further analysis (Fig.1). Table 1 presented the characteristics 124 of selected studies. Of the 10 studies, 7 were from China, 2 were from Iran, and 1 was from India. 125 Additionally, 7 studies were based on population and 3 based on hospital. Moreover, genotype 126 distributions in control group of each included study complied with Hardy-Weinberg 127 equilibriums (HWE) $(P>0.05)$ except only one study for one SNP (Erfani et al. 2006). The 128 detailed data of the allele frequency and genotype distribution as well as HWE from each study 129 were showed in Table 2.

\section{Meta-analysis results}


Seven studies containing 3,613 cases and 3,608 controls focused on breast cancer risk with

132

133

134

135

136

137

138

139

140

141

142

143

144

145

146

147

148

149

150

151

CTLA-4 rs231775 polymorphism. As presented in Table 3, significantly decreased risk was observed in the overall population in all the models except heterozygote $(\mathrm{G} v s . \mathrm{A}: \mathrm{OR}=0.86$, 95\% CI $=0.80-0.92, P=0.000$, Fig. $2 \mathrm{~A} ; \mathrm{GG} v s . \mathrm{AA}: \mathrm{OR}=0.68,95 \% \mathrm{CI}=0.57-0.81, P=0.000$;

$\mathrm{GG}$ vs. $\mathrm{AA}+\mathrm{AG}: \mathrm{OR}=0.79,95 \% \mathrm{CI}=0.71-0.87, P=0.000 ; \mathrm{AG}+\mathrm{GG} v s . \mathrm{AA}: \mathrm{OR}=0.85,95 \%$ $\mathrm{CI}=0.74-0.97, P=0.02 ;$ ). In subgroup analyses, rs231775 was also found to significantly reduce the breast cancer risk in Chinese and subgroup based on population under allelic, homozygous and recessive models.

There were 4 studies all of which were from China with 1,402 cases and 1,407 controls investigating the relationship between and breast cancer susceptibility and CTLA-4 rs3087243 polymorphism. The results presented a significantly lower breast cancer risk in homozygous and recessive genetic models in Chinese women (AA vs. GG: OR $=0.68,95 \%$ CI $=0.49-0.95$, $P=0.02$, Fig.2B; AA vs. $\mathrm{GG}+\mathrm{GA}: \mathrm{OR}=0.77,95 \% \mathrm{CI}=0.61-0.97, P=0.02$, .

For CTLA-4 rs733618 polymorphism, we aseessed 4 studies containing 1,560 cases and 1,489 controls. Overall, our analysis did not suggest any association between rs733618 and breast cancer susceptibility. However, when stratifying by source of control, rs733618 was observed to increase breast cancer risk based on population in three genetic models (C vs. T: OR $=1.19,95 \% \mathrm{CI}=1.05-1.34, P=0.007 ; \mathrm{CC} v s . \mathrm{TT}: \mathrm{OR}=1.37,95 \% \mathrm{CI}=1.05-1.78, P=0.02 ; \mathrm{CT}$ vs. $\mathrm{TT}: \mathrm{OR}=1.22,95 \% \mathrm{CI}=1.02-1.47, P=0.03)$.

Five studies involving 1656 cases and 1,625 controls investigated the breast cancer risk with CTLA-4 rs4553808 polymorphism. We observed a higher risk in overall analysis under three 
152 models $(\mathrm{G} v s . \mathrm{A}: \mathrm{OR}=1.34,95 \% \mathrm{CI}=1.16-1.53, P=0.000 ;$ AG vs. AA: $\mathrm{OR}=1.45,95 \% \mathrm{CI}=$

153 1.23-1.70, $P=0.000 ; \mathrm{AG}+\mathrm{GG}$ vs. $\mathrm{AA}: \mathrm{OR}=1.43,95 \% \mathrm{CI}=1.22-1.67, P=0.000$, Fig.2C). And

154 the results were similar in Chinese subgroup. When stratifying by source of control, rs 4553808

155 was also noted to increase breast cancer risk in allelic and heterozygous models based on

156 population.

157 Heterogeneity analysis and sensitivity analysis

As presented in Table 4, no obvious heterogeneity was detected for the four CTLA-4 polymorphisms in most of the genetic models. For the few in which existed significant heterogeneity $\left(\mathrm{I}^{2}>50 \%\right)$, random-effects model was applied.

Each study was sequentially removed to assess the impact of single study on the combined ORs. The result showed that the omission of any study didn't alter the overall estimations substantially, indicating that our meta-analysis results were robust (Fig.3).

\section{Publication bias}

We implemened Begg's funnel plot and Egger's test to asesess the publication bias. As shown in Fig.4, funnel plot failed to display obvious asymmetry. The Egger's test result didn't reveal any publication bias for the four SNPs in CTLA-4 gene and breast cancer risk either (Table

$5, P>0.05)$.

\section{Discussion}

It was reported that mutation in human $C T L A-4$ gene resulted in quantitative reduction of CTLA-4 expression and led to a severe immunoregulatory disorder (Kuehn et al. 2014). Several investigations have suggested that particular CTLA-4 gene polymorphisms are linked to cancer 
173 development or progression (Erfani et al. 2006; Tang et al. 2014; Wang et al. 2007). However,

174 the results from those studies remained conflicting. In one previous study, the author found that

175 rs733618 and rs4553808 polymorphisms in CTLA-4 increased the breast cancer risk whereas

176 rs231775 and rs3087243 polymorphisms did not have significant associations with breast cancer

177 risk(Li et al. 2012). However, in other studies, rs3087243 and rs 231775 polymorphisms were

178 found to reduce the risk of breast cancer while rs733618 did not associated with breast cancer

179 risk(Sun et al. 2008; Wang et al. 2007). Since CTLA-4 is important in carcinogenesis and single

180 study does not have enough statistical power to detect the effects, we carried out this meta-

analysis which synthesized the results of the included studies with a statistical analysis of the

data from these studies to draw a more reliable conclusion about the association between CTLA-4

SNPs and breast cancer susceptibility.

In present meta-analysis, we identified that CTLA-4 rs231775 had an association with breast

cancer susceptibility. We observed a significantly decreased risk in both overall and subgroup

analysis in different genetic models. Some previous meta-analyses have also involved the

relationship between rs231775 polymorphism and several tumor sites including breast cancer

(Gao et al. 2014; Geng et al. 2014; Wang et al. 2015; Zhang et al. 2011). The results suggested the A allele of rs231775 may contribute to breast cancer susceptibility. Our result confirmed that the A allele of CTLA-4 rs231775 polymorphism has more possibility to increase breast cancer risk than $G$ allele. Nevertheless, our study differs from theirs because we specifically focused on reliable. 
194 CTLA-4 rs3087243 polymorphism was found to decrease breast cancer risk under 195 homozygous and recessive genetic models in Chinese. Our results implied that individuals carry 196 AA genotype are less susceptible to breast cancer than those carry GG or (GG+GA) genotypes. 197 Previous studies also found that rs3087243 was associated with breast cancer susceptibility as a subgroup of several cancer sites (Yan et al. 2013; Zhao et al. 2014). The results were similar with our research, but our our meta-analysis included one more study and have more statistical power.

We didn't find any relationship between CTLA-4 rs733618 and breast cancer risk in the overall analysis under any genetic model. However, there was a higher risk in the populationbased group under all the genetic models except recessive model. Considering that we selected only four eligible studies and most of them were small-size sample $(<500)$, these results need to be taken with caution. One previous study found a positive signal of rs 733618 polymorphism with breast cancer ( $\mathrm{Li}$ et al. 2012) while other two studies showed negative signal (Erfani et al. 2006; Tang et al. 2014). So further researches with larger sample size should be designed and implemented to validate or refute these conclusions.

In contrast, $C T L A-4$ rs4553808 polymorphism was realated to an increased breast cancer risk in both overall and Chinese population in allelic, heterozygous and dominant models. This suggested that CTLA-4 $-1661 \mathrm{G}$ allele is more likely to be a risk factor of breast cancer than A allele. Previous meta-analysis also found rs4553808 may increase cancer risk especially for breast cancer (Geng et al. 2014; Yan et al. 2013; Zhao et al. 2014). But these studies investigated the association of this single SNP with various types of cancer while our study specifically focused on breast cancer and investigated several SNPs. Notably, for this SNP, the $P$-value of 
215 HWE in control of one study was less than 0.05(Erfani et al. 2006), suggesting that the study 216 population was not representative of a broad population. Nevertheless, we decided to keep this 217 study because deleting it did not affect the pooled ORs significantly.

218 Several limitations of our research should be noticed. Firstly, the sample size in this meta219 analysis was relatively small, especially for rs3087243, rs733618 and rs4553808 polymorphisms.

220 Secondly, our results need to be interpreted with caution since we did not find any studies from

221 Europe, Africa or America and most of the included studies were from China. Therefore, more

222 studies with large population and more ethnic groups are needed to provide sufficient statistical

223 power. Thirdly, other factors such as environmental variants, age, and living habit are generally

224 considered to contribute to cancer susceptibility. Lacking data of these factors for adjustment

225 may impact the estimation of breast cancer risk. Lastly, bias may still exist because we failed to

226 find any studies of other races and we did not have access to gray literature.

\section{Conclusion}

In summary, our meta-analysis suggests that rs231775, rs3087243 and rs4553808

polymorphisms in human $C T L A-4$ gene significantly associated with breast cancer susceptibility

in Asians, particularly in Chinese population. In consideration of the limitations of our work,

further large-scale studies including multi-racial population are required to confirm our findings.

232

233

234

235

\section{References}

Anjos S, Nguyen A, Ounissi-Benkalha H, Tessier MC, and Polychronakos C. 2002. A common autoimmunity predisposing signal peptide variant of the cytotoxic T-lymphocyte antigen 4 results in inefficient glycosylation of the susceptibility allele. Journal of Biological Chemistry 
277:46478-46486. DOI 10.1074/jbc.M206894200

Donner H, Rau H, Walfish PG, Braun J, Siegmund T, Finke R, Herwig J, Usadel KH, and Badenhoop K. 1997. CTLA4 alanine-17 confers genetic susceptibility to Graves' disease and to type 1 diabetes mellitus. Journal of Clinical Endocrinology and Metabolism 82:143-146. DOI 10.1210/jcem.82.1.3699

Dunn GP, Old LJ, and Schreiber RD. 2004. The three Es of cancer immunoediting. Annual Review of Immunology 22:329-360. DOI 10.1146/annurev.immunol.22.012703.104803

Erfani N, Razmkhah M, Talei AR, Pezeshki AM, Doroudchi M, Monabati A, and Ghaderi A. 2006. Cytotoxic T lymphocyte antigen-4 promoter variants in breast cancer. Cancer Genetics and Cytogenetics 165:114-120. DOI 10.1016/j.cancergencyto.2005.07.020

Gao X, Zhang S, Qiao X, Yao Y, Wang L, Dong D, Ma X, and Wang T. 2014. Association of cytotoxic T lymphocyte antigen $-4+49 \mathrm{~A} / \mathrm{G}$ polymorphism and cancer risk: An updated meta-analysis. Cancer Biomark 14:287-294. DOI 10.3233/CBM-140403

Geng R, Song F, Yang X, Sun P, Hu J, Zhu C, Zhu B, and Fan W. 2014. Association between cytotoxic T lymphocyte antigen-4 +49A/G, $-1722 \mathrm{~T} / \mathrm{C}$, and $-1661 \mathrm{~A} / \mathrm{G}$ polymorphisms and cancer risk: a metaanalysis. Tumour Biology 35:3627-3639. DOI 10.1007/s13277-013-1480-x

Ghaderi A, Yeganeh F, Kalantari T, Talei AR, Pezeshki AM, Doroudchi M, and Dehaghani AS. 2004. Cytotoxic T lymphocyte antigen-4 gene in breast cancer. Breast Cancer Research and Treattment 86:1-7. DOI 10.1023/B:BREA.0000032918.89120.8e

Higgins JPT, and Thompson SG. 2002. Quantifying heterogeneity in a meta-analysis. Statistics in Medicine 21:1539-1558. DOI 10.1002/Sim.1186

Hughes TA. 2006. Regulation of gene expression by alternative untranslated regions. Trends in Genetics 22:119-122. DOI 10.1016/j.tig.2006.01.001

Johnson GC, Esposito L, Barratt BJ, Smith AN, Heward J, Di Genova G, Ueda H, Cordell HJ, Eaves IA, Dudbridge F, Twells RC, Payne F, Hughes W, Nutland S, Stevens H, Carr P, Tuomilehto-Wolf E, Tuomilehto J, Gough SC, Clayton DG, and Todd JA. 2001. Haplotype tagging for the identification of common disease genes. Nature Genetics 29:233-237. DOI 10.1038/ng1001-233 
263

264

265

266

267

268

269

270

271

272

273

274

275

276

277

278

279

280

281

282

283

284

285

286

287

288

289

Kong FJ. 2010. Association between polymorphisms of CTLA-4, IL-10 gene and breast cancer in Chinese Han population. D. Med. Thesis, Fourth Military Medical University.

Kuehn HS, Ouyang W, Lo B, Deenick EK, Niemela JE, Avery DT, Schickel JN, Tran DQ, Stoddard J, Zhang Y, Frucht DM, Dumitriu B, Scheinberg P, Folio LR, Frein CA, Price S, Koh C, Heller T, Seroogy CM, Huttenlocher A, Rao VK, Su HC, Kleiner D, Notarangelo LD, Rampertaap Y, Olivier KN, McElwee J, Hughes J, Pittaluga S, Oliveira JB, Meffre E, Fleisher TA, Holland SM, Lenardo MJ, Tangye SG, and Uzel G. 2014. Immune dysregulation in human subjects with heterozygous germline mutations in CTLA4. Science 345:1623-1627. DOI $10.1126 /$ science. 1255904

Leach DR, Krummel MF, and Allison JP. 1996. Enhancement of antitumor immunity by CTLA-4 blockade. Science 271:1734-1736.

Li D, Zhang Q, Xu F, Fu Z, Yuan W, and Pang D. 2012. Association of CTLA-4 gene polymorphisms with sporadic breast cancer risk and clinical features in Han women of northeast China. Molecular and Cellular Biochemistry 364:283-290. DOI 10.1007/s11010-012-1228-8

Li H, Fu ZK, Wang LH, Li DL, Wu N, Zhang J, and Li DJ. 2008. Xi Bao Yu Fen Zi Mian Yi Xue Za Zhi 24:282-284.

Minhas S, Bhalla S, Shokeen Y, Jauhri M, Saxena R, Verma IC, and Aggarwal S. 2014. Lack of any association of the CTLA-4 +49 G/A polymorphism with breast cancer risk in a North Indian population. Asian Pacific Journal of Cancer Prevention 15:2035-2038.

Reeves GK, Pirie K, Green J, Bull D, and Beral V. 2012. Comparison of the effects of genetic and environmental risk factors on in situ and invasive ductal breast cancer. International Journal of Cancer 131:930-937. DOI 10.1002/ijc.26460

Ribas A, Glaspy JA, Lee Y, Dissette VB, Seja E, Vu HT, Tchekmedyian NS, Oseguera D, Comin-Anduix B, Wargo JA, Amarnani SN, McBride WH, Economou JS, and Butterfield LH. 2004. Role of dendritic cell phenotype, determinant spreading, and negative costimulatory blockade in dendritic cell-based melanoma immunotherapy. Journal of Immunotherapy 27:354-367.

Sun T, Zhou Y, Yang M, Hu Z, Tan W, Han X, Shi Y, Yao J, Guo Y, Yu D, Tian T, Zhou X, Shen H, and 
290

291

292

293

294

295

296

297

298

299

300

301

302

303

304

305

306

307

308

309

310

311

312

313

314

315

316
Lin D. 2008. Functional genetic variations in cytotoxic T-lymphocyte antigen 4 and susceptibility to multiple types of cancer. Cancer Research 68:7025-7034. DOI 10.1158/0008-5472.CAN-080806

Tang W, Qiu H, Jiang H, Sun B, Wang L, Yin J, and Gu H. 2014. Lack of association between cytotoxic T-lymphocyte antigen 4 (CTLA-4) -1722T/C (rs733618) polymorphism and cancer risk: from a case-control study to a meta-analysis. PLoS One 9:e94039. DOI 10.1371/journal.pone.0094039

Torre LA, Bray F, Siegel RL, Ferlay J, Lortet-Tieulent J, and Jemal A. 2015. Global cancer statistics, 2012. CA-A Cancer Journal for Clinicians 65:87-108. DOI 10.3322/caac.21262

Vandenborre K, Van Gool SW, Kasran A, Ceuppens JL, Boogaerts MA, and Vandenberghe P. 1999. Interaction of CTLA-4 (CD152) with CD80 or CD86 inhibits human T-cell activation. Immunology 98:413-421.

Walunas TL, Lenschow DJ, Bakker CY, Linsley PS, Freeman GJ, Green JM, Thompson CB, and Bluestone JA. 2011. Pillars article: CTLA-4 can function as a negative regulator of $\mathrm{T}$ cell activation. Immunity. 1994. 1: 405-413. Journal of Immunology 187:3466-3474.

Wang L, Jiang Z, Qiu H, Tang W, Duan T, and Wang L. 2015. Associations between CTLA-4 +49 A/G (rs231775) polymorphism and cancer risk: a meta-analysis based on 52 case-control studies. International Journal of Clinical and Experimental Medicine 8:6835-6851.

Wang L, Li D, Fu Z, Li H, and Jiang W. 2007. Association of CTLA-4 gene polymorphisms with sporadic breast cancer in Chinese Han population. BMC Cancer 7:173. DOI 10.1186/1471-2407$7-173$

Wang XB, Zhao X, Giscombe R, and Lefvert AK. 2002. A CTLA-4 gene polymorphism at position-318 in the promoter region affects the expression of protein. Genes and Immunity 3:233-234. DOI $10.1038 /$ sj.gene. 6363869

Yan Q, Chen P, Lu A, Zhao P, and Gu A. 2013. Association between CTLA-4 60G/A and -1661A/G polymorphisms and the risk of cancers: a meta-analysis. PLoS One 8:e83710. DOI 10.1371/journal.pone.0083710

Zhang B, Beeghly-Fadiel A, Long J, and Zheng W. 2011. Genetic variants associated with breast-cancer 
317

318

319 risk: comprehensive research synopsis, meta-analysis, and epidemiological evidence. Lancet Oncoogyl 12:477-488. DOI 10.1016/S1470-2045(11)70076-6

Zhao HY, Duan HX, and Gu Y. 2014. Meta-analysis of the cytotoxic T-lymphocyte antigen 4 gene +6230G/A polymorphism and cancer risk. Clinical and Translational Oncology 16:879-885. DOI 10.1007/s12094-014-1159-9

Zhifu Y, Mingli J, Shuang C, Fan W, Zhenkun F, Wangyang C, Lin Z, Guangxiao L, Yashuang Z, and Dianjun L. 2015. SNP-SNP interactions of immunity related genes involved in the CD28/B7 pathway with susceptibility to invasive ductal carcinoma of the breast. Gene 566:217-222. DOI 10.1016/j.gene.2015.04.04

Moher D, Liberati A, Tetzlaff J, and Altman DG. 2010. Preferred reporting items for systematic reviews and meta-analyses: the PRISMA statement. Int $J$ Surg 8:336-341. 10.1016/j.ijsu.2010.02.007

Wells GA, Shea B, O’Connell D, Peterson J, Welch V, Losos M, Tugwell P. 2014. The Newcastle- Ottawa Scale (NOS) for assessing the quality of nonrandomized studies in meta-analyses. Available at: http://www.ohri.ca/programs/clinical_epidemiology/ oxford.asp.

Petitti DB. 2001. Approaches to heterogeneity in meta-analysis. Stat Med 20:3625-3633.

Begg CB, and Mazumdar M. 1994. Operating characteristics of a rank correlation test for publication bias. Biometrics 50:1088-1101.

Egger M, Davey Smith G, Schneider M, and Minder C. 1997. Bias in meta-analysis detected by a simple, graphical test. Bmj 315:629-634. 


\section{Table 1 (on next page)}

Characteristics of the studies included in the meta-analysis. 


\begin{tabular}{|c|c|c|c|c|c|c|c|}
\hline First author & Year & Country & Ethnicity & $\begin{array}{c}\text { Genotyping } \\
\text { medthod }\end{array}$ & $\begin{array}{c}\text { Source of } \\
\text { control }\end{array}$ & $\begin{array}{l}\text { Total sample size } \\
\text { (case/control) }\end{array}$ & SNP \\
\hline $\mathrm{Yu}$ & 2015 & China & Chinese & PCR-RFLP & $\mathrm{PB}$ & $376 / 366$ & $1 ; 2 ; 3 ; 4$ \\
\hline Minhas & 2014 & India & Indian & PCR-RFLP & $\mathrm{PB}$ & $250 / 250$ & 1 \\
\hline Li D & 2012 & China & Chinese & PCR-RFLP & $\mathrm{PB}$ & $581 / 566$ & $1 ; 2 ; 3 ; 4$ \\
\hline Kong & 2010 & China & Chinese & PCR-RFLP & HB & $315 / 322$ & 4 \\
\hline Sun & $2008 \mathrm{a}$ & China & Chinese & PCR-RFLP & PB & $1060 / 1070$ & 1 \\
\hline Sun & $2008 b$ & China & Chinese & PCR-RFLP & $\mathrm{PB}$ & $1037 / 1070$ & 1 \\
\hline $\mathrm{LiH}$ & 2008 & China & Chinese & PCR-RFLP & HB & $328 / 327$ & $2 ; 3$ \\
\hline Wang & 2007 & China & Chinese & PCR-RFLP & PB & $117 / 148$ & $1 ; 2 ; 4$ \\
\hline Erfani & 2006 & Iran & Iranian & PCR-CTPP & PB & $283 / 245$ & $3 ; 4$ \\
\hline Ghaderi & 2004 & Iran & Iranian & PCR-RFLP & HB & $197 / 151$ & 1 \\
\hline
\end{tabular}

2 PCR: polymerase chain reaction; RFLP: restriction fragment length polymorphism; CTPP: confronting two 3 pairs primers; PB: population based; HB: hospital based; SNP: single-nucleotide polymorphism; SNP No.1:

$4+49 \mathrm{~A}>\mathrm{G}(\mathrm{rs} 231775), 2:+6230 \mathrm{G}>\mathrm{A}(\mathrm{rs} 3087243), 3:-1722 \mathrm{~T}>\mathrm{C}(\mathrm{rs} 733618), 4:-1661 \mathrm{~A}>\mathrm{G}(\mathrm{rs} 4553808)$

5

6 


\section{Table 2 (on next page)}

Genotype distributions and allele frequencies of CTLA-4 polymorphisms in cases and controls. 
1

\begin{tabular}{|c|c|c|c|c|c|c|c|c|c|c|c|c|c|}
\hline \multirow{3}{*}{ Study } & \multicolumn{8}{|c|}{ Genotype (N) } & \multicolumn{4}{|c|}{ Allele Frequency $(\mathrm{N})$} & \multirow{3}{*}{$\begin{array}{c}P \text { of } \\
\text { HWE }\end{array}$} \\
\hline & \multicolumn{4}{|c|}{ Case } & \multicolumn{4}{|c|}{ Control } & \multicolumn{2}{|c|}{ Case } & \multicolumn{2}{|c|}{ Control } & \\
\hline & total & AA & $\mathrm{AB}$ & $\mathrm{BB}$ & total & AA & $\mathrm{AB}$ & $\mathrm{BB}$ & A & B & A & B & \\
\hline \multicolumn{14}{|c|}{$+49 \mathrm{~A}>\mathrm{G}(\mathrm{rs} 231775)$} \\
\hline Yu 2015 & 376 & 174 & 175 & 27 & 366 & 174 & 157 & 35 & 523 & 229 & 505 & 227 & 0.96 \\
\hline Minhas2014 & 250 & 111 & 113 & 26 & 250 & 105 & 121 & 24 & 335 & 165 & 331 & 169 & 0.20 \\
\hline Li D 2012 & 576 & 49 & 281 & 246 & 553 & 54 & 243 & 256 & 379 & 773 & 351 & 755 & 0.74 \\
\hline Sun $2008 \mathrm{a}$ & 1060 & 101 & 485 & 474 & 1070 & 65 & 446 & 559 & 660 & 1406 & 576 & 1564 & 0.15 \\
\hline Sun $2008 b$ & 1037 & 100 & 455 & 482 & 1070 & 73 & 451 & 546 & 655 & 1419 & 597 & 1543 & 0.12 \\
\hline Wang 2007 & 117 & 48 & 59 & 10 & 148 & 55 & 70 & 23 & 155 & 79 & 180 & 116 & 0.93 \\
\hline Ghaderi2004 & 197 & 84 & 104 & 9 & 151 & 60 & 72 & 19 & 272 & 122 & 192 & 110 & 0.72 \\
\hline \multicolumn{14}{|c|}{$+6230 \mathrm{G}>\mathrm{A}(\mathrm{rs} 3087243)$} \\
\hline Yu 2015 & 376 & 257 & 110 & 9 & 366 & 252 & 103 & 11 & 624 & 128 & 607 & 125 & 0.90 \\
\hline Li D 2012 & 581 & 361 & 197 & 23 & 566 & 361 & 182 & 23 & 919 & 243 & 904 & 228 & 0.99 \\
\hline Li H 2008 & 328 & 32 & 124 & 172 & 327 & 20 & 114 & 193 & 188 & 468 & 154 & 500 & 0.57 \\
\hline Wang 2007 & 117 & 24 & 47 & 46 & 148 & 18 & 56 & 74 & 95 & 139 & 92 & 204 & 0.16 \\
\hline \multicolumn{14}{|c|}{$-1722 \mathrm{~T}>\mathrm{C}(\mathrm{rs} 733618)$} \\
\hline Yu 2015 & 376 & 123 & 186 & 67 & 366 & 137 & 166 & 63 & 432 & 320 & 440 & 292 & 0.30 \\
\hline Li D 2012 & 574 & 184 & 276 & 114 & 551 & 207 & 256 & 88 & 644 & 504 & 670 & 432 & 0.55 \\
\hline Li H 2008 & 328 & 125 & 163 & 40 & 327 & 111 & 168 & 48 & 413 & 243 & 390 & 264 & 0.22 \\
\hline Erfani 2006 & 282 & 225 & 54 & 3 & 245 & 204 & 41 & 0 & 504 & 60 & 449 & 41 & 0.15 \\
\hline \multicolumn{14}{|c|}{$-1661 \mathrm{~A}>\mathrm{G}(\mathrm{rs} 4553808)$} \\
\hline Yu 2015 & 376 & 273 & 91 & 12 & 366 & 281 & 78 & 7 & 637 & 115 & 640 & 92 & 0.56 \\
\hline Li D 2012 & 574 & 405 & 153 & 16 & 551 & 425 & 115 & 11 & 963 & 185 & 965 & 137 & 0.33 \\
\hline Kong 2010 & 315 & 204 & 105 & 6 & 322 & 241 & 76 & 5 & 513 & 117 & 558 & 86 & 0.72 \\
\hline Wang 2007 & 109 & 62 & 45 & 2 & 148 & 111 & 35 & 2 & 169 & 49 & 257 & 39 & 0.68 \\
\hline Erfani 2006 & 282 & 211 & 65 & 6 & 238 & 184 & 43 & 11 & 487 & 77 & 411 & 65 & 0.001 \\
\hline
\end{tabular}

2 A: the major allele; B: the minor allele; HWE: Hardy-Weinberg equilibrium 


\section{Table 3 (on next page)}

Meta-analysis results of CTLA-4 polymorphisms and $B C$ risk 
2

\begin{tabular}{|c|c|c|c|c|c|c|c|c|c|c|}
\hline \multirow{2}{*}{ SNP } & \multicolumn{2}{|c|}{$\mathrm{B}$ vs $\mathrm{A}$} & \multicolumn{2}{|c|}{$\mathrm{BB}$ vs $\mathrm{AA}$} & \multicolumn{2}{|c|}{$\mathrm{AB}$ vs $\mathrm{AA}$} & \multicolumn{2}{|c|}{$\mathrm{BB}$ vs $\mathrm{AA}+\mathrm{AB}$} & \multicolumn{2}{|c|}{$\mathrm{AB}+\mathrm{BB}$ vs $\mathrm{AA}$} \\
\hline & OR $(95 \% \mathrm{CI})$ & $P$ & OR $(95 \% \mathrm{CI})$ & $P$ & OR $(95 \% \mathrm{CI})$ & $P$ & OR $(95 \% \mathrm{CI})$ & $P$ & OR $(95 \% \mathrm{CI})$ & $P$ \\
\hline \multicolumn{11}{|c|}{$+49 \mathrm{~A}>\mathrm{G}(\mathrm{rs} 231775)$} \\
\hline Overall & $\begin{array}{c}0.86(0.80- \\
0.92)\end{array}$ & 0.000 & $\begin{array}{c}0.68(0.57- \\
0.81)\end{array}$ & 0.000 & $\begin{array}{c}0.92(0.80- \\
1.06)\end{array}$ & 0.23 & $\begin{array}{c}0.79(0.71- \\
0.87)\end{array}$ & 0.000 & $\begin{array}{c}0.85(0.74- \\
0.97)\end{array}$ & 0.02 \\
\hline Chinese & $\begin{array}{c}0.85(0.79- \\
0.92)\end{array}$ & 0.000 & $\begin{array}{c}0.68(0.56- \\
0.82)\end{array}$ & 0.000 & $\begin{array}{c}0.92(0.73- \\
1.16)\end{array}$ & 0.49 & $\begin{array}{c}0.79(0.71- \\
0.88)\end{array}$ & 0.000 & $\begin{array}{c}0.84(0.65- \\
1.08)\end{array}$ & 0.17 \\
\hline PB & $\begin{array}{c}0.86(0.80- \\
0.93)\end{array}$ & 0.000 & $\begin{array}{c}0.70(0.59- \\
0.84)\end{array}$ & 0.000 & $\begin{array}{c}0.91(0.78- \\
1.05)\end{array}$ & 0.19 & $\begin{array}{c}0.80(0.72- \\
0.89)\end{array}$ & 0.000 & $\begin{array}{c}0.85(0.69- \\
1.04)\end{array}$ & 0.12 \\
\hline \multicolumn{11}{|c|}{$+6230 \mathrm{G}>\mathrm{A}(\mathrm{rs} 3087243)$} \\
\hline Chinese & $\begin{array}{c}0.87(0.71- \\
1.07)\end{array}$ & 0.20 & $\begin{array}{c}0.68(0.49- \\
0.95)\end{array}$ & 0.02 & $\begin{array}{c}0.99(0.83- \\
1.19)\end{array}$ & 0.94 & $\begin{array}{c}0.77(0.61- \\
0.97)\end{array}$ & 0.02 & $\begin{array}{c}0.87(0.65- \\
1.17)\end{array}$ & 0.36 \\
\hline PB & $\begin{array}{c}0.91(0.71- \\
1.17)\end{array}$ & 0.48 & $\begin{array}{c}0.75(0.50- \\
1.12)\end{array}$ & 0.15 & $\begin{array}{c}1.03(0.85- \\
1.25)\end{array}$ & 0.76 & $\begin{array}{c}0.77(0.54- \\
1.09)\end{array}$ & 0.14 & $\begin{array}{c}1.00(0.82- \\
1.20)\end{array}$ & 0.99 \\
\hline \multicolumn{11}{|c|}{$-1722 \mathrm{~T}>\mathrm{C}(\mathrm{rs} 733618)$} \\
\hline Overall & $\begin{array}{c}1.09(0.93- \\
1.29)\end{array}$ & 0.29 & $\begin{array}{c}1.15(0.79- \\
1.68)\end{array}$ & 0.47 & $\begin{array}{c}1.13(0.96- \\
1.32)\end{array}$ & 0.15 & $\begin{array}{c}1.11(0.90- \\
1.37)\end{array}$ & 0.32 & $\begin{array}{c}1.14(0.98- \\
1.33)\end{array}$ & 0.09 \\
\hline Chinese & $\begin{array}{c}1.07(0.88- \\
1.29)\end{array}$ & 0.51 & $\begin{array}{c}1.12(0.77- \\
1.63)\end{array}$ & 0.55 & $\begin{array}{c}1.120 .94- \\
1.33()\end{array}$ & 0.22 & $\begin{array}{c}1.10(0.89- \\
1.35)\end{array}$ & 0.39 & $\begin{array}{c}1.11(0.86- \\
1.43)\end{array}$ & 0.43 \\
\hline PB & $\begin{array}{c}1.19(1.05- \\
1.34)\end{array}$ & 0.007 & $\begin{array}{c}1.37(1.05- \\
1.78)\end{array}$ & 0.02 & $\begin{array}{c}1.22(1.02- \\
1.47)\end{array}$ & 0.03 & $\begin{array}{c}1.21(0.96- \\
1.54)\end{array}$ & 0.11 & $\begin{array}{c}1.26(1.06- \\
1.50)\end{array}$ & 0.01 \\
\hline \multicolumn{11}{|c|}{$-1661 \mathrm{~A}>\mathrm{G}(\mathrm{rs} 4553808)$} \\
\hline Overall & $\begin{array}{c}1.34(1.16- \\
1.53)\end{array}$ & 0.000 & $\begin{array}{c}1.22(0.78- \\
1.92)\end{array}$ & 0.38 & $\begin{array}{c}1.45(1.23- \\
1.70)\end{array}$ & 0.000 & $\begin{array}{c}1.12(0.72- \\
1.76)\end{array}$ & 0.61 & $\begin{array}{c}1.43(1.22- \\
1.67)\end{array}$ & 0.000 \\
\hline Chinese & $\begin{array}{c}1.41(1.21- \\
1.63)\end{array}$ & 0.000 & $\begin{array}{c}1.59(0.95- \\
2.67)\end{array}$ & 0.08 & $\begin{array}{c}1.47(1.24- \\
1.75)\end{array}$ & 0.000 & $\begin{array}{c}1.45(0.86- \\
2.43)\end{array}$ & 0.16 & $\begin{array}{c}1.48(1.25- \\
1.75)\end{array}$ & 0.000 \\
\hline PB & $\begin{array}{c}1.30(1.11- \\
1.52)\end{array}$ & 0.001 & $\begin{array}{c}1.19(0.73- \\
1.94)\end{array}$ & 0.48 & $\begin{array}{c}1.40(1.17- \\
1.68)\end{array}$ & 0.000 & $\begin{array}{c}1.11(0.68- \\
1.80)\end{array}$ & 0.68 & $\begin{array}{c}1.38(1.16- \\
1.64)\end{array}$ & 0.000 \\
\hline HWE & $\begin{array}{c}1.41(1.21- \\
1.63)\end{array}$ & 0.000 & $\begin{array}{c}1.59(0.95- \\
2.67)\end{array}$ & 0.08 & $\begin{array}{c}1.47(1.24- \\
1.75)\end{array}$ & 0.000 & $\begin{array}{c}1.45(0.86- \\
2.43)\end{array}$ & 0.16 & $\begin{array}{c}1.48(1.25- \\
1.75)\end{array}$ & 0.000 \\
\hline
\end{tabular}

3 A: the major allele; B: the minor allele; CI: confidence interval; OR: odds ratio; PB: population based; HB:

4 hospital based; SNP: single-nucleotide polymorphism; HWE: subgroup excluding the study departing from

5 HWE 


\section{Table 4(on next page)}

Heterogeneity-analysis results of CTLA-4 polymorphisms and $B C$ risk 
1

\begin{tabular}{|c|c|c|c|c|c|c|c|c|c|c|c|c|c|c|c|}
\hline \multirow{2}{*}{ SNP } & \multicolumn{3}{|c|}{$\mathrm{B}$ vs $\mathrm{A}$} & \multicolumn{3}{|c|}{$\mathrm{BB}$ vs $\mathrm{AA}$} & \multicolumn{3}{|c|}{$\mathrm{AB}$ vs $\mathrm{AA}$} & \multicolumn{3}{|c|}{$\mathrm{BB}$ vs $\mathrm{AA}+\mathrm{AB}$} & \multicolumn{3}{|c|}{$\mathrm{AB}+\mathrm{BB}$ vs $\mathrm{AA}$} \\
\hline & $\mathrm{I}^{2}$ & $P$ & EM & $\mathrm{I}^{2}$ & $P$ & EM & $\mathrm{I}^{2}$ & $P$ & EM & $\mathrm{I}^{2}$ & $P$ & EM & $\mathrm{I}^{2}$ & $P$ & EM \\
\hline \multicolumn{16}{|c|}{$+49 \mathrm{~A}>\mathrm{G}(\mathrm{rs} 231775)$} \\
\hline Overall & $0 \%$ & 0.46 & $\mathrm{~F}$ & $45 \%$ & 0.09 & $\mathrm{~F}$ & $29 \%$ & 0.21 & $\mathrm{~F}$ & $27 \%$ & 0.22 & $\mathrm{~F}$ & $41 \%$ & 0.12 & $\mathrm{~F}$ \\
\hline Chinese & $12 \%$ & 0.34 & $\mathrm{~F}$ & $40 \%$ & 0.15 & $\mathrm{~F}$ & $51 \%$ & 0.09 & $\mathrm{R}$ & $0 \%$ & 0.59 & $\mathrm{~F}$ & $60 \%$ & 0.04 & $\mathrm{R}$ \\
\hline PB & $6 \%$ & 0.38 & $\mathrm{~F}$ & $39 \%$ & 0.14 & $\mathrm{~F}$ & $39 \%$ & 0.15 & $\mathrm{~F}$ & $0 \%$ & 0.56 & $\mathrm{~F}$ & $51 \%$ & 0.07 & $\mathrm{R}$ \\
\hline \multicolumn{16}{|c|}{$+6230 \mathrm{G}>\mathrm{A}(\mathrm{rs} 3087243)$} \\
\hline Chinese & $58 \%$ & 0.07 & $\mathrm{R}$ & $8 \%$ & 0.36 & $\mathrm{~F}$ & $0 \%$ & 0.38 & $\mathrm{~F}$ & $0 \%$ & 0.78 & $\mathrm{~F}$ & $53 \%$ & 0.09 & $\mathrm{R}$ \\
\hline $\mathrm{PB}$ & $60 \%$ & 0.08 & $\mathrm{R}$ & $24 \%$ & 0.27 & $\mathrm{~F}$ & $16 \%$ & 0.31 & $\mathrm{~F}$ & $0 \%$ & 0.58 & $\mathrm{~F}$ & $46 \%$ & 0.16 & $\mathrm{~F}$ \\
\hline \multicolumn{16}{|c|}{$-1722 \mathrm{~T}>\mathrm{C}(\mathrm{rs} 733618)$} \\
\hline Overall & $52 \%$ & 0.10 & $\mathrm{R}$ & $51 \%$ & 0.10 & $\mathrm{R}$ & $7 \%$ & 0.36 & $\mathrm{~F}$ & $35 \%$ & 0.22 & $\mathrm{~F}$ & $39 \%$ & 0.18 & $\mathrm{~F}$ \\
\hline Chinese & $64 \%$ & 0.06 & $\mathrm{R}$ & $59 \%$ & 0.09 & $\mathrm{R}$ & $37 \%$ & 0.21 & $\mathrm{~F}$ & $31 \%$ & 0.23 & $\mathrm{~F}$ & $57 \%$ & 0.10 & $\mathrm{R}$ \\
\hline PB & $0 \%$ & 0.74 & $\mathrm{~F}$ & $0 \%$ & 0.45 & $\mathrm{~F}$ & $0 \%$ & 0.99 & $\mathrm{~F}$ & $0 \%$ & 0.37 & $\mathrm{~F}$ & $0 \%$ & 0.98 & $\mathrm{~F}$ \\
\hline \multicolumn{16}{|c|}{$-1661 \mathrm{~A}>\mathrm{G}(\mathrm{rs} 4553808)$} \\
\hline Overall & $27 \%$ & 0.24 & $\mathrm{~F}$ & $9 \%$ & 0.35 & $\mathrm{~F}$ & $14 \%$ & 0.32 & $\mathrm{~F}$ & $6 \%$ & 0.37 & $\mathrm{~F}$ & $24 \%$ & 0.26 & $\mathrm{~F}$ \\
\hline Chinese & $0 \%$ & 0.48 & $\mathrm{~F}$ & $0 \%$ & 0.99 & $\mathrm{~F}$ & $32 \%$ & 0.22 & $\mathrm{~F}$ & $0 \%$ & 0.98 & $\mathrm{~F}$ & $24 \%$ & 0.27 & $\mathrm{~F}$ \\
\hline $\mathrm{PB}$ & $39 \%$ & 0.18 & $\mathrm{~F}$ & $31 \%$ & 0.23 & $\mathrm{~F}$ & $27 \%$ & 0.25 & $\mathrm{~F}$ & $30 \%$ & 0.24 & $\mathrm{~F}$ & $34 \%$ & 0.21 & $\mathrm{~F}$ \\
\hline HWE & $0 \%$ & 0.48 & $\mathrm{~F}$ & $0 \%$ & 0.99 & $\mathrm{~F}$ & $32 \%$ & 0.22 & $\mathrm{~F}$ & $0 \%$ & 0.98 & $\mathrm{~F}$ & $24 \%$ & 0.27 & F \\
\hline
\end{tabular}

2 EM: Effects model; F: fixed effects model; R: random effects model; PB: population based; HB: hospital

3 based; SNP: single-nucleotide polymorphism; HWE: subgroup excluding the study departing from HWE 


\section{Table 5 (on next page)}

Egger's test result of CTLA-4 polymorphisms and BC risk based on allele frequency 
1

\begin{tabular}{cccccc}
\hline SNP & Coefficient & SE & $\mathrm{t}$ & $P$ & $95 \%$ CI \\
\hline rs231775 & 0.71 & 1.13 & 0.63 & 0.557 & $-2.19-3.61$ \\
rs3087243 & -5.19 & 3.20 & -1.62 & 0.246 & $-18.94-0.56$ \\
rs733618 & -0.03 & 3.17 & -0.01 & 0.993 & $-13.67-13.61$ \\
rs4553808 & 1.26 & 2.82 & 0.45 & 0.686 & $-7.70-10.21$ \\
\hline
\end{tabular}


Figure 1

Flow chart of the studies selection

134 Records identified through search of database up to July 18, 2016

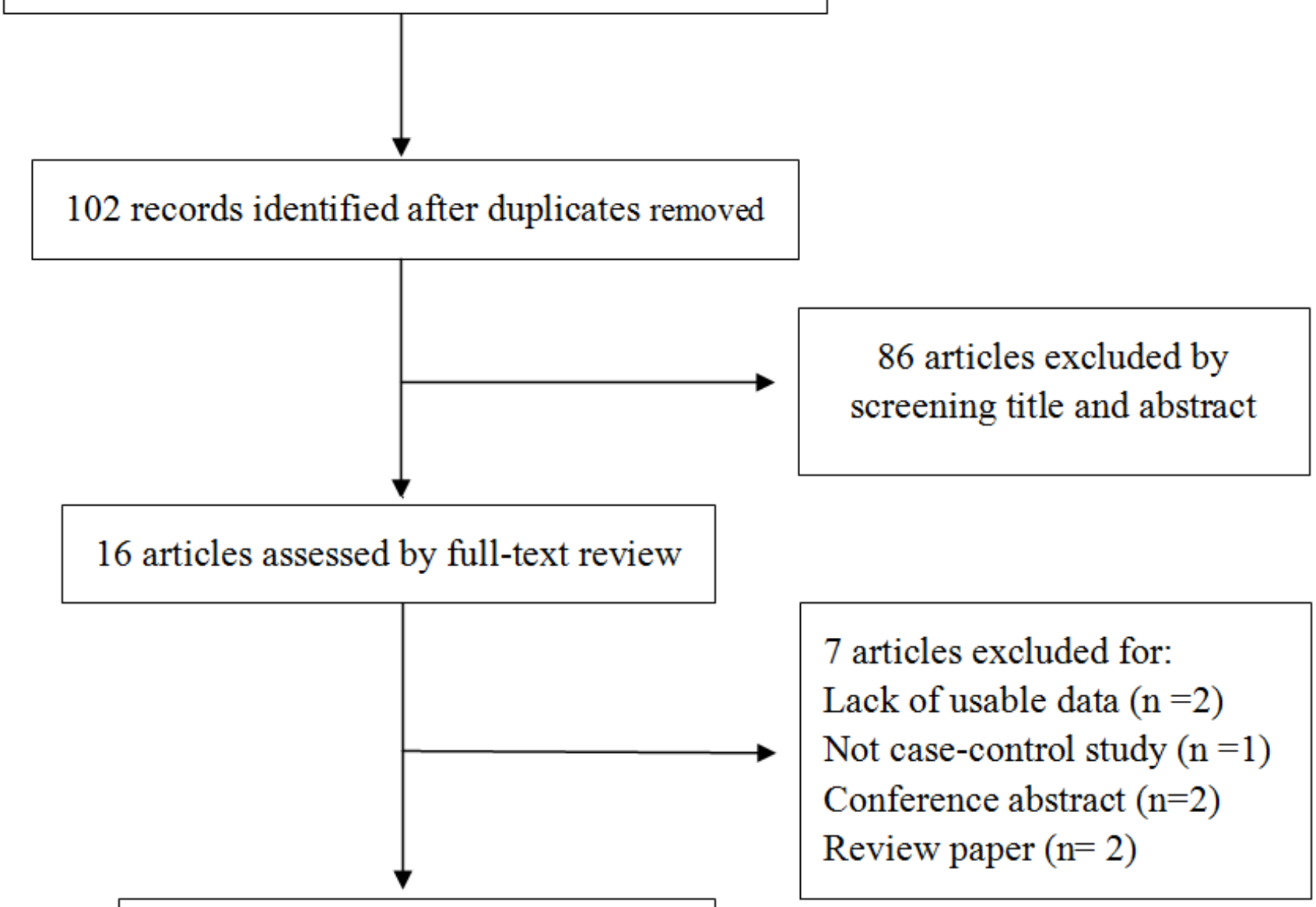

10 studies from 9 articles included in the meta-analysis 
Figure 2

Forest plots of CTLA-4 polymorphisms and breast cancer risk

A) rs231775 under G vs. A; B) rs3087243 under AA vs. GG; C) rs4553808 under AG+GG vs. AA. The squares and horizontal lines correspond to the study-specific OR and $95 \% \mathrm{Cl}$. The area of the squares reflects the weight (inverse of the variance). The diamond represents the summary OR and $95 \% \mathrm{Cl}$.

A

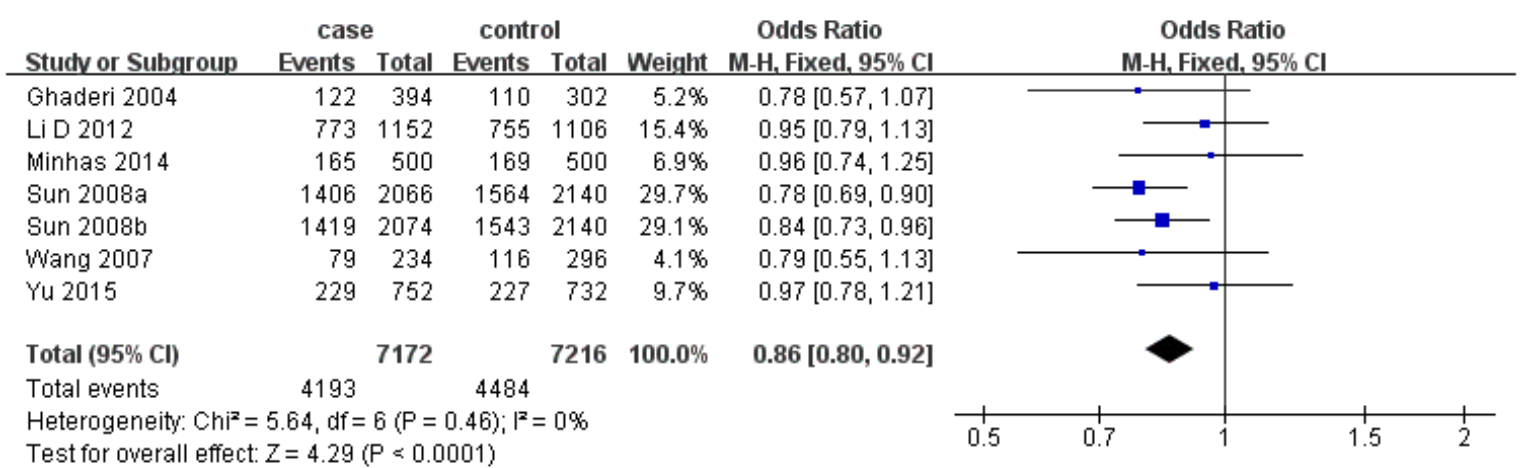

B

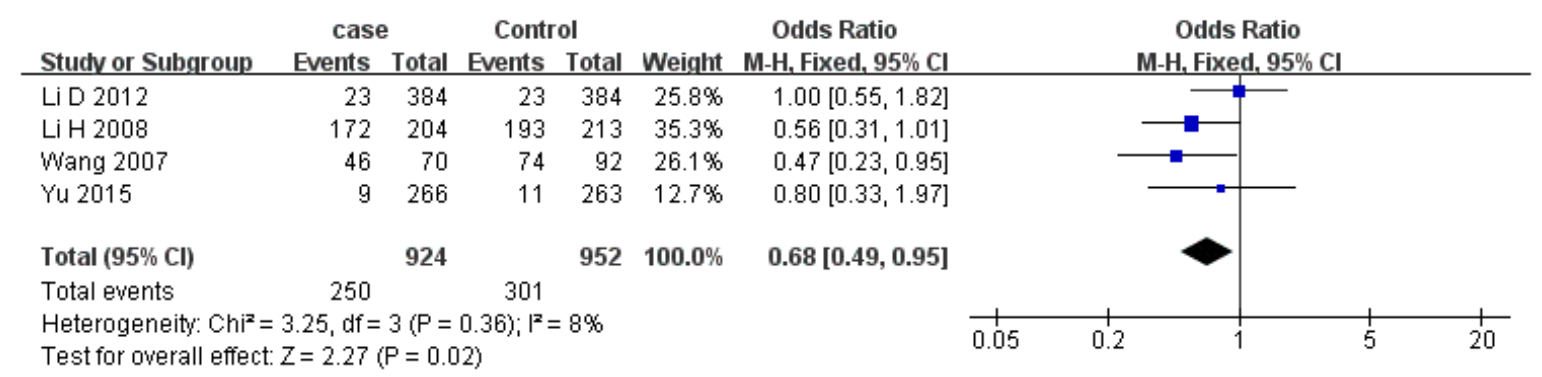

C

\begin{tabular}{|c|c|c|c|c|c|c|c|c|c|c|}
\hline Studv or Subgroup & \multicolumn{2}{|c|}{ case } & \multicolumn{2}{|c|}{ Control } & Weight & $\begin{array}{c}\text { Odds Ratio } \\
\text { M-H, Fixed, 95\% Cl }\end{array}$ & \multicolumn{3}{|c|}{$\begin{array}{c}\text { Odds Ratio } \\
\text { M-H, Fixed, 95\% Cl }\end{array}$} & \\
\hline Erfani 2006 & 71 & 282 & 54 & 238 & $16.4 \%$ & $1.15[0.76,1.72]$ & & & & \\
\hline Kong 2010 & 111 & 315 & 81 & 322 & $19.4 \%$ & $1.62[1.15,2.28]$ & & & & \\
\hline Li D 2012 & 169 & 574 & 126 & 551 & $34.0 \%$ & $1.41[1.08,1.84]$ & & & & \\
\hline Wang 2007 & 47 & 109 & 37 & 148 & $6.7 \%$ & $2.27[1.34,3.87]$ & & & & \\
\hline Yu 2015 & 103 & 376 & 85 & 366 & $23.4 \%$ & $1.25[0.89,1.74]$ & & & & \\
\hline Total $(95 \% \mathrm{CI})$ & & 1656 & & 1625 & $100.0 \%$ & $1.43[1.22,1.67]$ & & & & \\
\hline Total events & 501 & & 383 & & & & & & & \\
\hline $\begin{array}{l}\text { Heterogeneity: } \mathrm{Chi}^{2} \\
\text { Test for overall effec }\end{array}$ & $\begin{array}{l}5.24, \mathrm{df}= \\
Z=4.47\end{array}$ & $\begin{array}{l}4(P= \\
P<0.0\end{array}$ & $\begin{array}{l}0.26) ;\left.\right|^{2}= \\
0001)\end{array}$ & $=24 \%$ & & & 0.2 & 0.5 & 1 & \\
\hline
\end{tabular}


Figure 3

Sensitivity analysis of CTLA-4 polymorphisms and breast cancer risk

A) rs231775 under G vs. A; B) rs3087243 under AA vs. GG+GA; C) rs733618 under TC vs. TT;

D) rs4553808 under G vs. A. Each point represents the pooled OR after omitting single study in left column. The two ends of the dotted lines represent the $95 \% \mathrm{Cl}$.
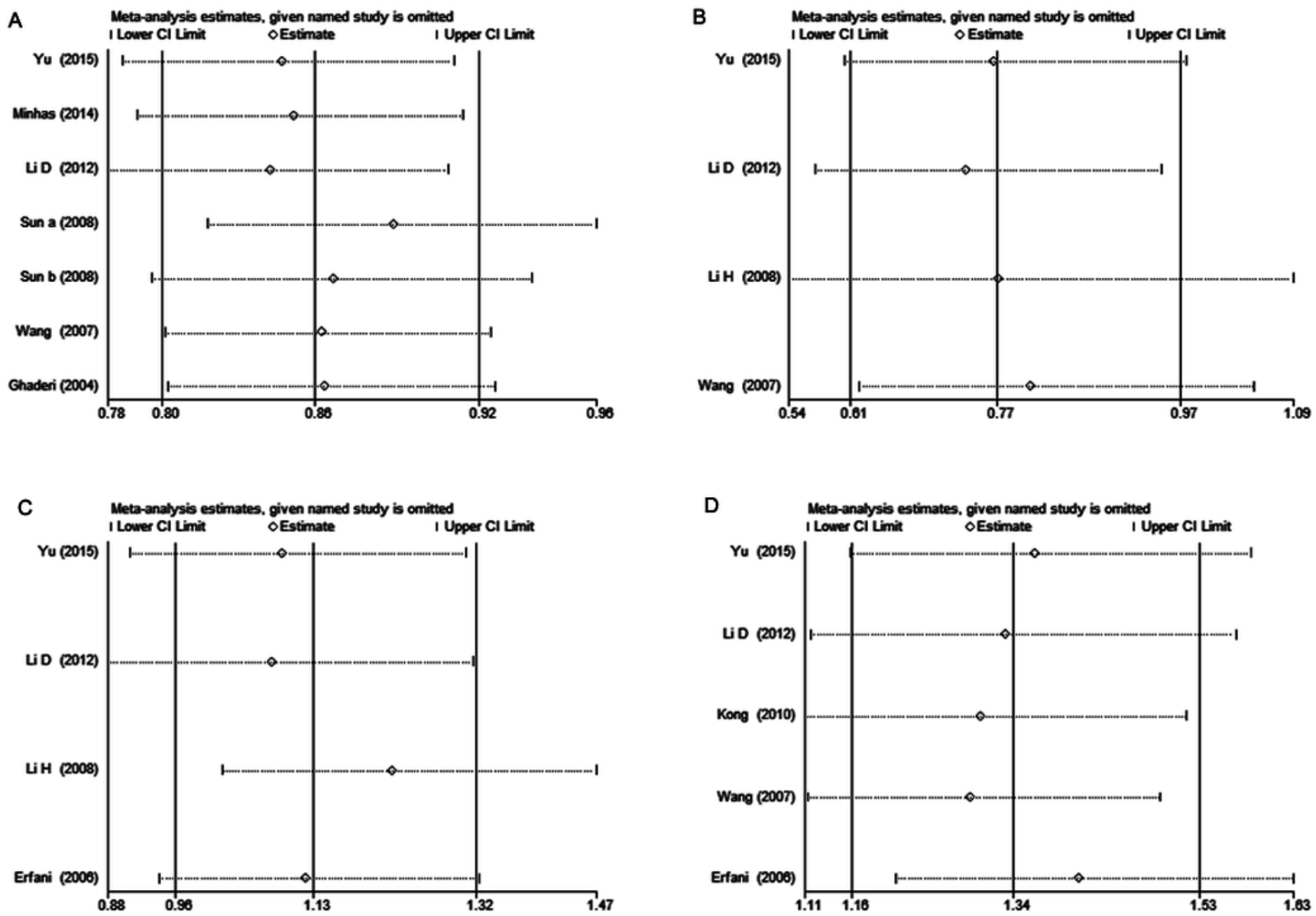
Figure 4

Begg's funnel plots of publication bias for the association of CTLA-4 polymorphisms and breast cancer risk

A) rs231775, B) rs3087243, C) rs733618, D) rs4553808 under allelic model. Each point represents a single study for the indicated association.
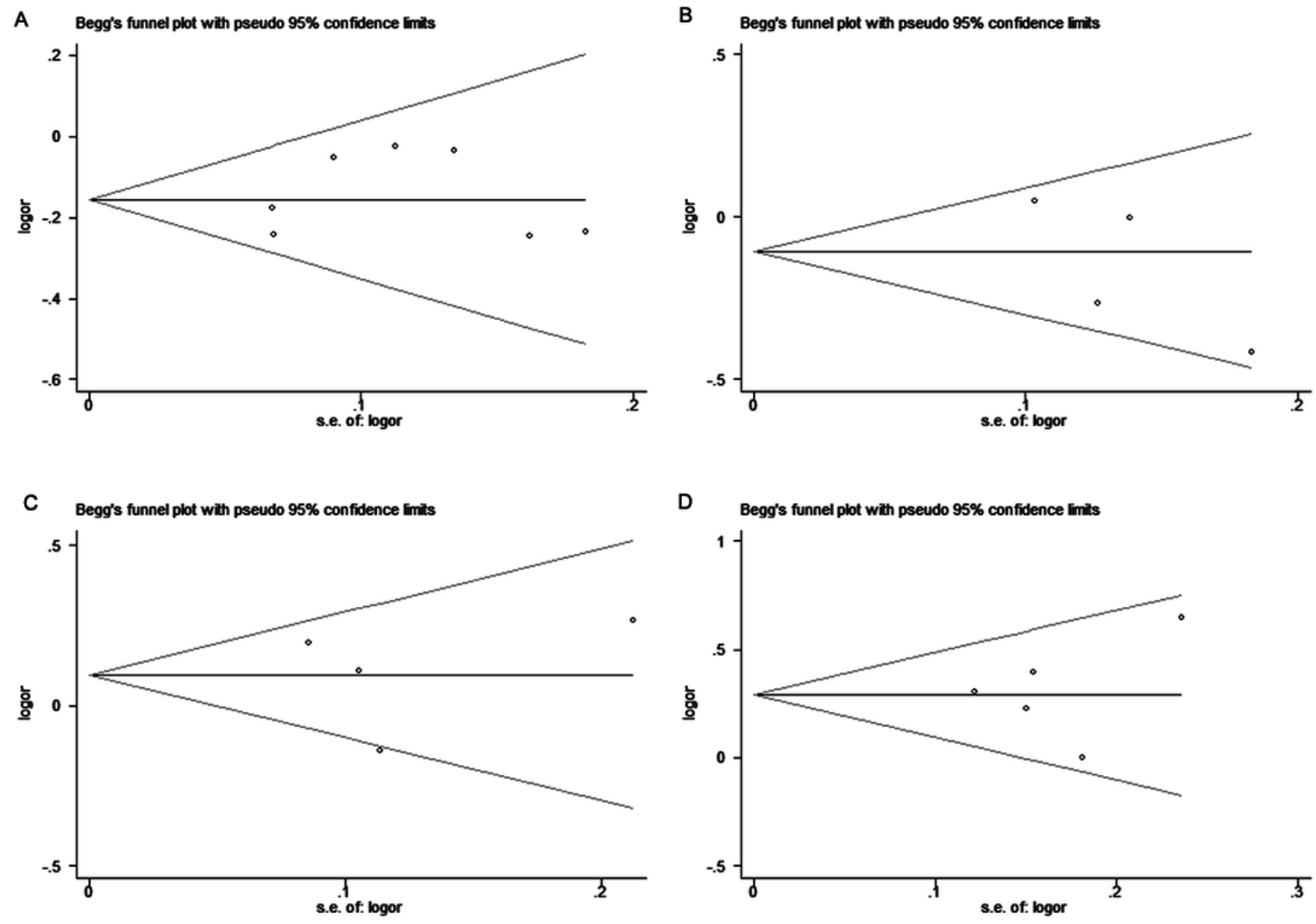